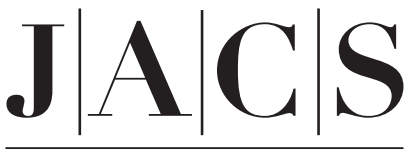

A R T I C L E S

Published on Web 07/22/2008

\title{
Structure of an F430 Variant from Archaea Associated with Anaerobic Oxidation of Methane
}

\author{
Stefan Mayr, ${ }^{\dagger}$ Christopher Latkoczy, ${ }^{\ddagger}$ Martin Krüger, ${ }^{\S, \#}$ Detlef Günther, ${ }^{\ddagger}$ \\ Seigo Shima, ${ }^{\text {" }}$ Rudolf K. Thauer, ${ }^{\text {" }}$ Friedrich Widdel, ${ }^{\S}$ and Bernhard Jaun ${ }^{*, \dagger}$ \\ Laboratory of Organic Chemistry, ETH Zurich, Wolfgang-Pauli-Strasse 10, \\ 8093 Zurich, Switzerland, Laboratory of Inorganic Chemistry, ETH Zurich, \\ Wolfgang-Pauli-Strasse 10, 8093 Zurich, Switzerland, Max Planck Institute for Marine \\ Microbiology, Celsiusstrasse 1, 28359 Bremen, Germany, and Max Planck Institute for \\ Terrestrial Microbiology, Karl-von-Frisch-Strasse, 35043 Marburg, Germany
}

Received April 21, 2008; E-mail: jaun@org.chem.ethz.ch

\begin{abstract}
Microbial mats collected at cold methane seeps in the Black Sea carry out anaerobic oxidation of methane (AOM) to carbon dioxide using sulfate as the electron acceptor. These mats, which predominantly consist of sulfate-reducing bacteria and archaea of the ANME-1 and ANME-2 type, contain large amounts of proteins very similar to methyl-coenzyme $\mathrm{M}$ reductase from methanogenic archaea. Mass spectrometry of mat samples revealed the presence of two nickel-containing cofactors in comparable amounts, one with the same mass as coenzyme F430 from methanogens $(\mathrm{m} / \mathrm{z}=905)$ and one with a mass that is $46 \mathrm{Da}$ higher $(m / z=951)$. The two cofactors were isolated and purified, and their constitution and absolute configuration were determined. The cofactor with $\mathrm{m} / \mathrm{z}=905$ was proven to be identical to coenzyme F430 from methanogens. For the $\mathrm{m} / z=951$ species, high resolution ICP-MS pointed to $\mathrm{F} 430+\mathrm{CH}_{2} \mathrm{~S}$ as the molecular formula, and LA-ICP-SF MS finally confirmed the presence of one sulfur atom per nickel. Esterification gave two stereoisomeric pentamethyl esters with $\mathrm{m} / \mathrm{z}=1021$, which could be purified by reverse phase HPLC and were subjected to comprehensive NMR analysis, allowing determination of their constitution and configuration as $\left(17^{2} S\right)-17^{2}$-methylthio-F430 pentamethyl ester and $\left(17^{2} R\right)-17^{2}$-methylthioF430 pentamethyl ester. The corresponding diastereoisomeric pentaacids could also be separated by HPLC and were correlated to the esters via mild hydrolysis of the latter. Equilibration of the pentaacids under acid catalysis showed that the $\left(17^{2} \mathrm{~S}\right)$ isomer is the naturally occurring albeit thermodynamically less stable one. The more stable $\left(17^{2} R\right)$ isomer ( $80 \%$ at equilibrium) is an isolation artifact generated under the acidic conditions necessary for the isolation of the cofactors from the calcium carbonate-encrusted mats.
\end{abstract}

\section{Introduction}

Coenzyme F430, the hydrocorphinoid nickel complex 1, is the prosthetic group of methyl-coenzyme M reductase (MCR), the key enzyme in biological methane formation by methanogenic archaea. ${ }^{1}$ Its structure is well established based on spectroscopic studies of isolated coenzyme F430 and its partial synthetic derivatives $^{2-7}$ and, more recently, on high resolution $\mathrm{X}$-ray structure analysis of the holoenzyme in the inactive $\mathrm{Ni}$ (II)

\footnotetext{
${ }^{\dagger}$ Laboratory of Organic Chemistry, ETH Zurich.

$\$$ Laboratory of Inorganic Chemistry, ETH Zurich.

${ }^{\S}$ Max Planck Institute for Marine Microbiology, Bremen.

${ }^{\text {II }}$ Max Planck Institute for Terrestrial Microbiology, Marburg.

\# Current address: Federal Institute for Geosciences and Natural Resources, Hannover, Germany.

(1) Jaun, B.; Thauer, R. K. Metal Ions Life Sci. 2007, 2, 323-356.

(2) Pfaltz, A.; Jaun, B.; Fässler, A.; Eschenmoser, A.; Jaenchen, R.; Gilles, H. H.; Diekert, G.; Thauer, R. K. Helv. Chim. Acta 1982, 65, 82865.

(3) Livingston, D. A.; Pfaltz, A.; Schreiber, J.; Eschenmoser, A.; AnkelFuchs, D.; Moll, J.; Jaenchen, R.; Thauer, R. K. Helv. Chim. Acta 1984, 67, 334-351.

(4) Fässler, A.; Kobelt, A.; Pfaltz, A.; Eschenmoser, A.; Bladon, C.; Battersby, A. R.; Thauer, R. K. Helv. Chim. Acta 1985, 68, 22872298.

(5) Pfaltz, A.; Livingston, D. A.; Jaun, B.; Diekert, G.; Thauer, R. K.; Eschenmoser, A. Helv. Chim. Acta 1985, 68, 1338-58.
}

form. ${ }^{8}$ All methanogenic species investigated so far contain a methyl-coenzyme $\mathrm{M}$ reductase and coenzyme F430 with its characteristic mass of $\mathrm{m} / \mathrm{z}=905$.

Over the last years, microbial consortia that oxidize methane and reduce sulfate according to eq 1) under strictly anoxic conditions were discovered in different marine habitats such as cold methane seeps or methane hydrate deposits ${ }^{9,10}$ (for review see ref 11).

$$
\mathrm{CH}_{4}+\mathrm{SO}_{4}{ }^{2-} \rightarrow \mathrm{HCO}_{3}{ }^{-}+\mathrm{HS}^{-}+\mathrm{H}_{2} \mathrm{O}
$$

The process of anaerobic methane oxidation (AOM) is of enormous ecological importance because it prevents the escape of the highly effective greenhouse gas methane into the ocean water

(6) Faerber, G.; Keller, W.; Kratky, C.; Jaun, B.; Pfalz, A.; Spinner, C.; Kobelt, A.; Eschenmoser, A. Helv. Chim. Acta 1991, 74, 697-716.

(7) Won, H.; Olson, K. D.; Wolfe, R. S.; Summers, M. F. J. Am. Chem. Soc. 1990, 112, 2178-2184.

(8) Ermler, U.; Grabarse, W.; Shima, S.; Goubeaud, M.; Thauer, R. K. Science 1997, 278, 1457-1462.

(9) Boetius, A.; Ravenschlag, K.; Schubert, C. J.; Rickert, D.; Widdel, F.; Gieseke, A.; Amann, R.; Jorgensen, B. B.; Witte, U.; Pfannkuche, O. Nature 2000, 407, 623-626.

(10) Hinrichs, K. U.; Hayes, J. M.; Sylva, S. P.; Brewer, P. G.; DeLong, E. F. Nature 1999, 398, 802-805. 


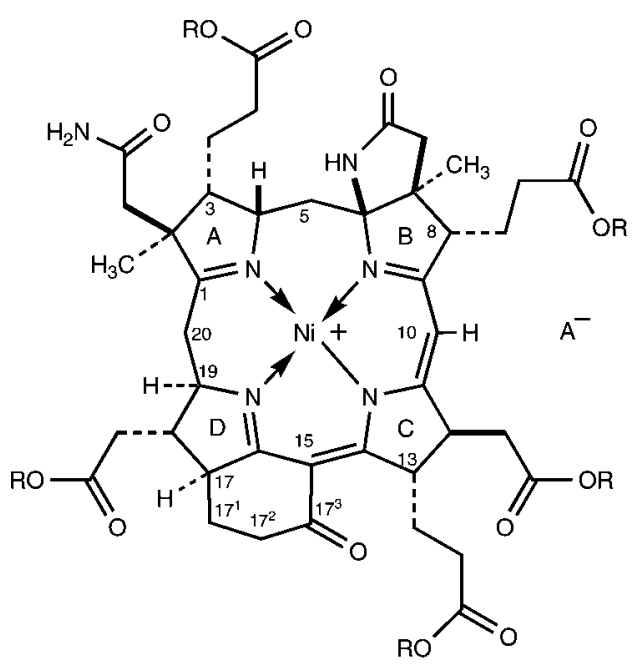

$1 \mathrm{R}=\mathrm{H} \quad$ coenzyme $\mathrm{F} 430$

$2 R=$ Me coenzyme $\mathrm{F} 430$ pentamethyl ester

and, eventually, into the atmosphere. ${ }^{11}$ The existence of microorganisms that are able to functionalize the inert $\mathrm{C}-\mathrm{H}$ bond of methane at low temperature and without oxygen, the obligate cosubstrate of classical methane monooxygenases, is mechanistically highly intriguing from the chemical point of view.

The consortia carrying out AOM consist mainly of archaea belonging to the ANME-1 and/or ANME-2 clusters, both being related to the methanogenic order Methanosarcinales, and of sulfate-reducing bacteria. Methanotrophic archaea have been shown to contain homologues of MCR and other enzymes involved in the methanogenic pathway by genetic analysis of whole consortia. ${ }^{12}$ Samples collected at cold methane seeps at Hydrate Ridge ${ }^{13}$ as well as in the Black Sea ${ }^{14}$ were shown to carry out AOM in the laboratory. Biochemical analysis of mats from the Black Sea, which consist of naturally highly enriched consortia, revealed that they contain large amounts of at least two nickel-proteins (protein I: $7 \%$ and protein II: $3 \%$ of total cell protein) with an absorption spectrum typical for the F430 chromophore. ${ }^{15,16}$ The constituent subunits and their $\mathrm{N}$-terminal sequences indicate that these proteins are close homologues of MCR from methanogens. Although still indirect, this evidence as a whole suggests that methanotrophic archaea might functionalize methane by reversing the methane forming step catalyzed by MCR in methanogens using a similar enzyme with a nickel corphinoid at the active site. MALDI-TOF MS analysis of mat material revealed the presence of two nickelcontaining compounds, one with $\mathrm{m} / \mathrm{z}=905$, the mass of coenzyme F430, the other with $m / z=951$. MS analysis of the purified proteins I and II showed that the latter contained the cofactor with $\mathrm{m} / \mathrm{z}=$ 905 , whereas protein I contained the new variant with $\mathrm{m} / z=951$.

Here, we report on the analysis of the nickel cofactors isolated from natural microbial mats, the proof that the $\mathrm{m} / \mathrm{z}=905$

(11) Reeburgh, W. S. Chem. Rev. 2007, 107, 486-513.

(12) Hallam, S. J.; Putnam, N.; Preston, C. M.; Detter, J. C.; Rokhsar, D.; Richardson, P. M.; DeLong, E. F. Science 2004, 305, 1457-1462.

(13) Nauhaus, K.; Boetius, A.; Krüger, M.; Widdel, F. Environ. Microbiol. 2002, 4, 296-305.

(14) Michaelis, W.; Seifert, R.; Nauhaus, K.; Treude, T.; Thiel, V.; Blumenberg, M.; Knittel, K.; Gieseke, A.; Peterknecht, K.; Pape, T.; Boetius, A.; Amann, R.; Jørgensen, B. B.; Widdel, F.; Peckmann, J.; Pimenov, N.; Gulin, M. B. Science 2002, 297, 1013-1015.

(15) Krüger, M.; Meyerdierks, A.; Glockner, F. O.; Amann, R.; Widdel, F.; Kube, M.; Reinhardt, R.; Kahnt, J.; Böcher, R.; Thauer, R. K.; Shima, S. Nature 2003, 426, 878-81.

(16) Shima, S.; Thauer, R. K. Curr. Opin. Microbiol. 2005, 8, 643-648. compound is identical to coenzyme F430 from methanogens, and the elucidation of the constitution and configuration of the new $m / z=951$ variant of coenzyme F430.

\section{Results}

A total of four raw coenzyme isolates, extracted from mats collected by a submersible during two expeditions (2001, 2004) to the Black Sea site, were used for the analysis (for a detailed workflow for the four isolates see Scheme SO in the Supporting Information). Isolate no. 1 decomposed. ${ }^{17}$ Isolates no. 2,3 , and 4 contained, according to the UV/vis spectra, a total of 1.20, 2.47, and $4.44 \mu \mathrm{mol}$, respectively, of F430 chromophore. Analytical HPLC on HYPERCARB of crude isolates no. 2, 3, and 4 with detection at $430 \mathrm{~nm}$ showed a considerable number of components which were separately collected and analyzed by MALDI-TOF MS (see chromatogram in Supporting Information, Figure S1). Before further analysis, half of isolate no. 2 and all of isolate no. 4 were converted to the pentamethyl esters (see below) yielding mixtures of compounds with $\mathrm{m} / \mathrm{z}=$ 975 and 1021 (Table 1 and Figure 1).

Identification of the Major $m / z=905$ Component as Coenzyme F430. The first major peak in the HPLC chromatogram corresponds to a component with $\mathrm{m} / \mathrm{z}=905$, which was identified as coenzyme F430 (1) by coinjection with a sample isolated from the methanogen Methanobacter thermoautotrophicum. The identity of this component with the cofactor from methanogens was later also confirmed on the level of the corresponding pentamethyl esters (2) by HPLC coinjection and comparison of the NMR spectra.

Molecular Formula of the $m / z=951$ Species. As a first step, isolate no. 2 was desalted and analyzed by high resolution MALDI-ICR MS with the goal to obtain the exact mass difference between the $\mathrm{m} / \mathrm{z}=905$ and $\mathrm{m} / \mathrm{z}=951$ components. For a two-point calibration, coenzyme F430 pentamethyl ester 2 with its exactly known mass of $\mathrm{m} / \mathrm{z}=975.36446$ was added to the sample to provide the first calibration point while the $m / z=905$ component $(F 430,1)$ with its exactly known mass of $m / z=905.28621$ was used as the second calibration point. The resulting mass difference was $45.99014 \pm 0.003$ Da. Although the precision was not sufficient to allow an unequivocal determination of the molecular formula, the chemically most reasonable elementary composition among the range of possibilities calculated with a limit of $\pm 8 \times 10^{-3}$ Da was $+\mathrm{CH}_{2} \mathrm{~S}$ (Scheme S2 in the Supporting Information).

Verification of the Presence of One Sulfur Atom by LA-ICPSF MS. To confirm the presence of a single sulfur atom in the $\mathrm{m} / \mathrm{z}=951$ component, we determined the Ni/S mass ratio by direct element analysis using laser ablation inductively coupled plasma sector field mass spectrometry (LA-ICP-SF MS) of isolate no. 3 and several samples of the pentamethyl esters (see below) of isolate no. 2 (with a known molar ratio of the $\mathrm{m} / \mathrm{z}=$ 1021 and $\mathrm{m} / \mathrm{z}=975$ components as determined by HPLC and MS analysis of each peak). Furthermore we analyzed pure component $\mathrm{F}$ (Figure $1 ; \mathrm{m} / \mathrm{z}=1021$ ) and F430 pentamethyl ester (2) from methanogens as a control. Because of the low amount of sample collected from HPLC, a microsampling technique for the determination of the $\mathrm{Ni}$ to $\mathrm{S}$ ratio was required.

(17) Isolate no. 1 was subjected to NMR analysis in TFE- $d_{3}$ and then in TFE- $d_{3}$ with $5 \%$ trifluoroacetic acid- $d$ without any purification. However, because of paramagnetism, the spectra showed only strongly broadened lines and were unsuitable for interpretation. After 2 days, the UV/vis spectra indicated that the sample had largely decomposed and no further analysis was done with isolate no. 1. 
Table 1. Determination of the Ni/S Molar Ratio by ICP-MS for the Pentamethyl Esters of Isolate No. 2, Raw Isolate No. 3 (pentaacids) and for HPLC-Pure Pentamethyl Ester (isomer F) of the F430 $\mathrm{m} / \mathrm{z}=951$ Variant

\begin{tabular}{ccccc}
\hline Sample & $\begin{array}{c}\text { Molecular mass of } \\
\text { components }\end{array}$ & $\begin{array}{c}\text { Expected } \\
\text { Ni/S molar ratio } \\
\text { according to } \\
\text { HPLC integrals }\end{array}$ & $\begin{array}{c}\text { Ni/S molar ratio from } \\
\text { ICP-MS counts } \\
\text { (single line scans) }\end{array}$ \\
\hline Pentamethyl esters & & & & \\
\hline
\end{tabular}

Therefore, LA-ICP-SF MS was applied. A few microliterdroplets of the sample were dried on a quartz glass carrier and analyzed (further details are given in the Experimental Section). The results listed in Table 1 unequivocally show that the $\mathrm{m} / \mathrm{z}$ $=951$ variant contains one mole of sulfur per mole of nickel.

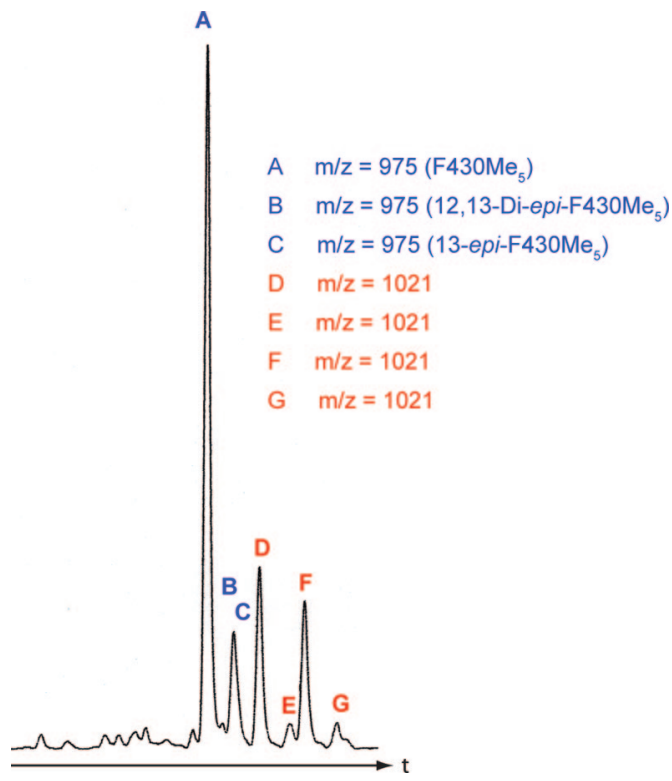

Figure 1. HPLC chromatogram of isolate no. 4 after esterification to the pentamethyl esters. Major peaks are labeled with fraction designators and with the $m / z$ values as determined by MS. Components A-C were identified as indicated by coinjection with the known F430 derivatives.
Structure Elucidation for the New $(m / z=951)$ Coenzyme F430 Variant. Square planar, tetracoordinate $\mathrm{Ni}^{\mathrm{II}} \mathrm{F} 430$ derivatives are diamagnetic (low-spin $\mathrm{d}^{8}$ ) and suitable for high resolution NMR analysis. However, the nickel center has a high propensity to coordinate additional ligands in the axial positions and the resulting five- and six-coordinate complexes are paramagnetic (high-spin $\mathrm{d}^{8}$ ). Because of fast ligand exchange, even very small molar fractions of such high-spin forms induce line broadening and paramagnetic shifts in the NMR spectra. The resulting short $\mathrm{T}_{2}$-relaxation times make it impossible to acquire 2D spectra such as HMBC that are based on coherence transfer via small scalar couplings. So far, 2,2,2-trifluoroethanol (TFE) is the only known solvent that is polar enough to dissolve the native pentaacid of F430 from methanogens (1) without inducing a low-spin/high-spin transition by coordinating axially to the nickel(II) center. However, even in thoroughly purified and dried TFE- $d_{3}$, the spectra of F430 show a small residual line broadening as compared to the sharp spectra of the pentamethyl ester in noncoordinating solvents such as $\mathrm{CD}_{2} \mathrm{Cl}_{2}$ or TFE- $d_{3} / \mathrm{CD}_{2} \mathrm{Cl}_{2} 1: 4$. Initial attempts to measure NMR spectra of the isolates from mats in TFE- $d_{3}$ gave very broad lines for all F430 related components and indicated that the new $\mathrm{m} / \mathrm{z}=$ 951 variant shares its high coordination tendency with the known $\mathrm{m} / \mathrm{z}=905$ form. In analogy to the procedure that led to success in the structure elucidation of F430 from methanogens, we therefore decided to first try to convert the native pentaacids into the pentamethyl esters and to attempt both separation of the crude isolate mixture by HPLC and NMR analysis on the level of the pentaesters. 
Table 2. ${ }^{1} \mathrm{HNMR}$ Assignments for the Pentamethyl Esters 5 and 6 with $\mathrm{m} / z=1021$, the Native Pentaacid from Isolate No. 3 (3) and Comparison with Data for Coenzyme F430 Pentamethyl Ester (2) and Coenzyme F430 (1)

\begin{tabular}{|c|c|c|c|c|c|}
\hline atom & $\begin{array}{l}\left(17^{2} \mathrm{~S}\right)-17^{2} \text {-methylthio- } \\
\text { F430 pentamethyl } \\
\text { ester (5) in } \mathrm{CD}_{2} \mathrm{Cl}_{2} / \mathrm{TFE}-\mathrm{d}_{3}\end{array}$ & $\begin{array}{l}\left(17^{2} R\right)-17^{2} \text {-methylthio- } \\
\text { F430 pentamethyl } \\
\text { ester }(6) \text { in } \mathrm{CD}_{2} \mathrm{Cl}_{2} / \mathrm{TFE}-d_{3}\end{array}$ & $\begin{array}{l}\mathrm{F} 430 \text { pentamethyl } \\
\text { ester (2) in } \mathrm{CD}_{2} \mathrm{Cl}_{2} / \mathrm{TFE}-d_{3}\end{array}$ & $\begin{array}{l}\left(17^{2} S\right)-17^{2} \text {-methylthio- } \\
\text { F430 (3) in TFE- } d_{3}\end{array}$ & $\begin{array}{l}\text { coenzyme F430 } \\
\text { (1) in TFE- } d_{3}\end{array}$ \\
\hline $\mathrm{H} 2^{1 \prime \prime}$ & 2.58 & 2.57 & 2.58 & 2.64 & 2.60 \\
\hline $\mathrm{CH}_{3}-\mathrm{C} 2$ & 1.06 & 1.06 & 1.06 & 1.11 & 1.08 \\
\hline $\mathrm{H} 3$ & 2.55 & 2.54 & 2.62 & 2.66 & 2.60 \\
\hline $\mathrm{H} 3^{1 \prime \prime}$ & 1.59 & 1.58 & 1.57 & 1.70 & 1.65 \\
\hline $\mathrm{H} 3^{1,}$ & 1.75 & 1.75 & 1.75 & 1.82 & 1.77 \\
\hline $\mathrm{H} 4$ & 4.38 & 4.37 & 4.39 & 4.51 & 4.45 \\
\hline H5" & 1.42 & 1.39 & 1.45 & 1.51 & 1.48 \\
\hline $\mathrm{H} 5^{\prime}$ & 1.81 & 1.81 & 1.82 & 2.00 & 1.95 \\
\hline $\mathrm{H} 7^{1 \prime \prime}$ & 2.41 & 2.41 & 2.38 & 2.53 & 2.49 \\
\hline $\mathrm{H} 7^{1 \prime}$ & 2.46 & 2.47 & 2.45 & 2.55 & 2.49 \\
\hline $\mathrm{CH}_{3}-\mathrm{C} 7$ & 1.18 & 1.18 & 1.17 & 1.22 & 1.18 \\
\hline $\mathrm{CH}_{3} \mathrm{O}-\mathrm{C} 8^{3}$ & 3.73 & & 3.71 & & \\
\hline $\mathrm{H} 10$ & 5.78 & 5.74 & 5.73 & 5.95 & 5.91 \\
\hline $\mathrm{H} 12$ & 3.07 & 3.08 & 3.07 & 3.17 & 3.13 \\
\hline $\mathrm{H} 12^{1}$ & 2.78 & 2.81 & $2.75 / 2.71$ & 2.80 & 2.67 \\
\hline $\mathrm{CH}_{3} \mathrm{O}-\mathrm{C} 12^{2}$ & 3.66 & & 3.65 & & \\
\hline $\mathrm{H} 13$ & 3.83 & 3.81 & 3.82 & 4.00 & 3.91 \\
\hline $\mathrm{H} 13^{1 \prime \prime}$ & 1.57 & 1.73 & 1.60 & 1.80 & 1.71 \\
\hline $\mathrm{H} 13^{1 \prime}$ & 1.87 & 1.98 & 1.89 & 1.96 & 1.93 \\
\hline $\mathrm{H} 13^{2 \prime \prime}$ & 2.17 & 2.25 & 2.15 & 2.11 & 2.09 \\
\hline $\mathrm{H} 13^{2 \prime}$ & 2.36 & & 2.31 & 2.35 & 2.29 \\
\hline $\mathrm{CH}_{3} \mathrm{O}-\mathrm{C}^{3}{ }^{3}$ & 3.64 & & 3.64 & & \\
\hline H17 & 2.86 & 2.94 & 2.73 & 3.00 & 2.83 \\
\hline $\mathrm{H} 17^{1 \prime \prime}$ & 1.92 & 2.22 & 1.77 & 2.01 & 1.78 \\
\hline
\end{tabular}

Esterification of isolate no. 4 (ca. $4.4 \mu \mathrm{mol} \mathrm{F430} \mathrm{chro-}$ mophore) in methanol $/ p$ - $\mathrm{TsOH}$ according to the procedure established for F430 pentamethyl ester (2) gave a mixture of pentamethyl esters with $\mathrm{m} / \mathrm{z}=975$ and $\mathrm{m} / \mathrm{z}=1021$, respectively (total yield in F430 chromophore >99\%). The analytical RPHPLC chromatogram (Figure 1) revealed the presence of at least six components which were then separated on a semipreparative RP-HPLC column and analyzed by MS and UV/vis. The two major isomers with $\mathrm{m} / \mathrm{z}=1021$ (HPLC peaks D and F in Figure 1) were both isolated (500-600 nmol each) and subjected to a comprehensive NMR analysis in $\mathrm{CD}_{2} \mathrm{Cl}_{2} / \mathrm{TFE}-d_{3}$ 4:1. Minor peaks $\mathrm{B}$ and $\mathrm{C}$ were identified by coinjection as the known isolation artifacts 12,13 -di-epi-F430Me $\mathrm{M}_{5}$ and 13-epi-F430Me respectively. According to their UV/vis spectra and mass, minor components $\mathrm{E}$ and $\mathrm{G}$ (Figure 1) are diastereoisomers of $\mathrm{D}$ and $\mathrm{F}$, probably also at centers $\mathrm{C} 12$ and $\mathrm{C} 13$. However, the very small isolated amounts of these minor components did not allow verification of this presumption by NMR.

Constitution of the Pentamethyl Esters with $\mathrm{m} / \mathrm{z}=1021$ (isomers D and F). 1. Isomer D. The $1 \mathrm{D}{ }^{1} \mathrm{H}$ NMR spectrum revealed the presence of $5 \mathrm{CH}_{3} \mathrm{O}$-methyl ester signals, consistent with the mass of $\mathrm{m} / \mathrm{z}=1021$, and confirming that the $\mathrm{m} / \mathrm{z}=$ 951 variant is a pentacarboxylic acid like F430 from methanogens. A singlet at $2.16 \mathrm{ppm}$ (ca. $3 \mathrm{H}$, overlapping with other signals) with the corresponding ${ }^{13} \mathrm{C}$-signal $\left(\mathrm{CH}_{3}\right.$ from edited $\mathrm{HSQC}$ ) at $12.9 \mathrm{ppm}$ indicated the presence of a $\mathrm{CH}_{3} \mathrm{~S}$-function, consistent with the HiRes-ICR MS and IPC-MS findings. The $\mathrm{CH}_{3} \mathrm{~S}$ - protons showed a three-bond coupling (HMBC) to a methine carbon resonating at $51.0 \mathrm{ppm}$ which is correlated over one bond to a proton signal at $3.56 \mathrm{ppm}$ (HSQC). The location of this methine group, to which the $\mathrm{CH}_{3} \mathrm{~S}$ substituent must be attached, within the hydrocorphinoid framework required full analysis of the proton and carbon signals by DQF-COSY, TOCSY, multiplicity-edited HSQC, and HMBC. Starting from $\mathrm{H} 4$ and the spin system $\mathrm{H}_{2} 20-\mathrm{H} 19$ with their characteristic chemical shifts, all nonexchangeable protons and all protonbearing carbons in rings $\mathrm{A}, \mathrm{B}$, and $\mathrm{C}$, including the side chains, could be assigned as compiled in Tables 2 and 3. Comparison of chemical shifts and 2D correlations with the fully assigned spectra for F430 pentamethyl ester from methanogens (2) shows that these regions of the hydrocorphinoid ligand are unchanged in the new variant with $\mathrm{m} / \mathrm{z}=1021$. The position of the $\mathrm{CH}_{3} \mathrm{~S}$ substituent could be determined as follows (Figure 2): H18 and H17 were assigned from cross-peaks in DQF-COSY. H17 (2.86 $\mathrm{ppm}$ ) is further coupled to two geminal protons at 2.48 and 1.92 ppm, which are assigned to $\mathrm{H} 17^{1 \prime}$ and $\mathrm{H} 17^{1 \prime \prime}$, respectively. $\mathrm{H} 17^{1 " \prime}$ shows a large coupling, and $\mathrm{H} 17^{1 \prime}$ a small one, to the 
Table 3. ${ }^{13} \mathrm{C}$ NMR Assignments for the Pentamethyl Esters 5 and 6 with $\mathrm{m} / \mathrm{z}=1021$, the Native Pentaacid from Isolate No. 3 (3) and Comparison with Data for Coenzyme F430 Pentamethyl Ester (2) and Coenzyme F430 (1)

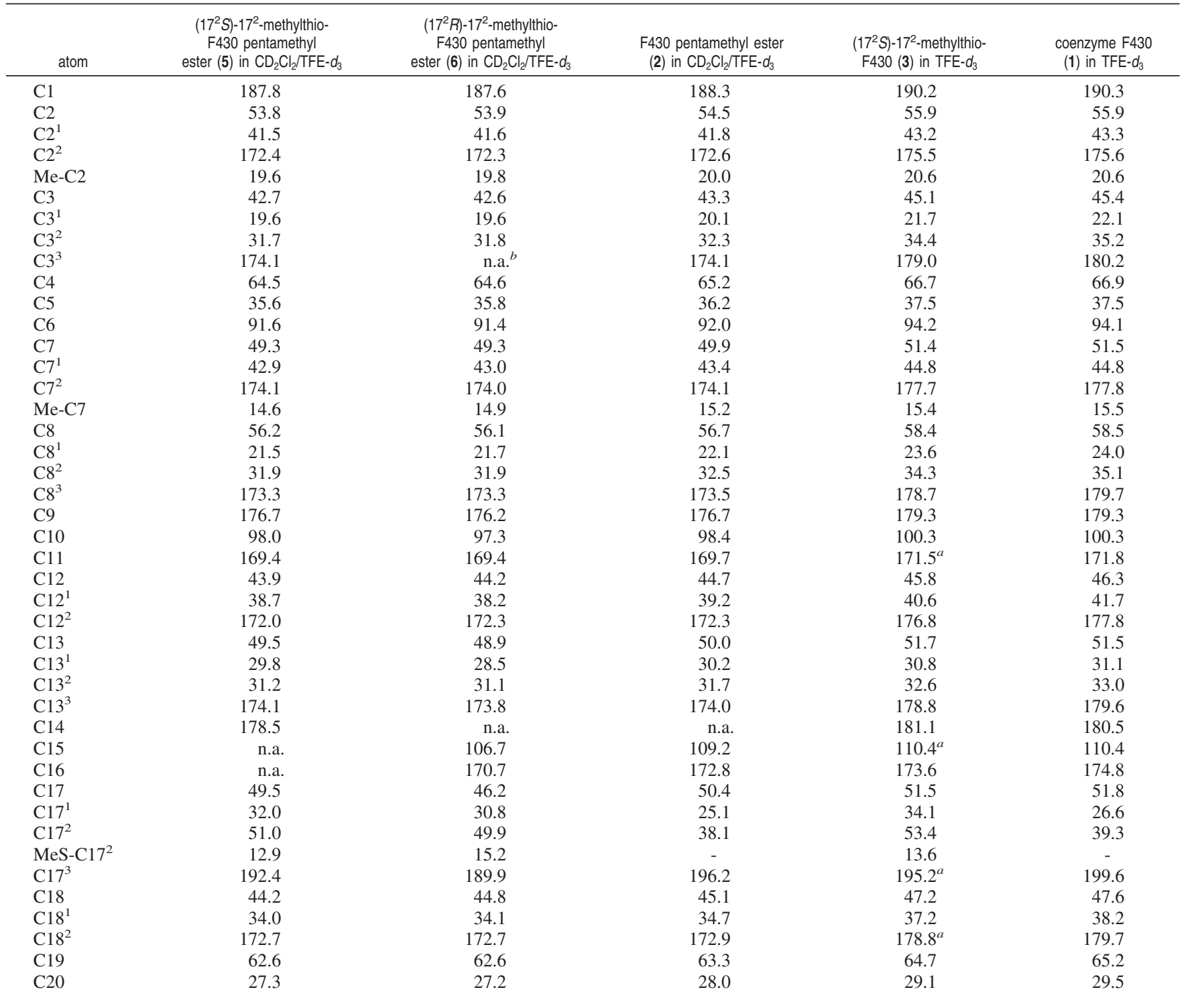

${ }^{a}$ No HMBC correlations detected. Assigned from the $1 \mathrm{D}{ }^{13} \mathrm{C}$ spectrum by analogy of chemical shifts with coenzyme F430 (1). ${ }^{b}$ n.a.: not assigned

proton at $3.56 \mathrm{ppm}$ that is correlated to the $\mathrm{CH}_{3} \mathrm{~S}$ protons via a three-bond coupling (HMBC). Therefore, the $\mathrm{CH}_{3} \mathrm{~S}$ group is bound to $\mathrm{C} 17^{2}$ and the signal at $3.56 \mathrm{ppm}$ is assigned to $\mathrm{H} 17^{2}$. A series of HMBC correlations as depicted in Figure $2 \mathrm{c}$ and listed in Table S4 corroborate this partial structure in the sixmembered carbocycle. In particular, both $\mathrm{H} 17^{1}$ protons (as well as $\mathrm{H}_{17^{2}}$ ) exhibit correlations to the keto group at $17^{3}$ with its characteristic chemical shift of $192.4 \mathrm{ppm}$ and are at the same time correlated to $\mathrm{C} 18$.

2. Isomer F. Assignments for isomer $F$ were done on the basis of the same type of spectra (Table S5 in Supporting Information) as for isomer D. Again, all protons and proton-bearing carbons in rings $\mathrm{A}-\mathrm{C}$ with their side chains were almost unchanged with respect to both F430 pentamethyl ester from methanogens and isomer D. The largest chemical shift differences to isomer D were found for the protons and carbons in the six-membered ring.

For isomer $\mathrm{F}$, the two $\mathrm{H} 17^{1}$ protons are practically isochronous $(2.22 \mathrm{ppm})$ as indicated by a single DQF-COSY crosspeak to $\mathrm{H} 17$ and a methylene-type cross-peak phase in the multiplicity-edited HSQC. The connectivity in the six membered ring is based on $\mathrm{HMBC}$ cross-peaks between $\mathrm{CH}_{3} \mathrm{~S}$ and $\mathrm{C}_{17}{ }^{2}$, between $\mathrm{H} 17^{2}$ and $\mathrm{C} 17$ as well as $\mathrm{C} 17^{3}$, and between $\mathrm{H}_{2} 17^{1}$ and $\mathrm{C} 17^{3}$ and $\mathrm{C} 16$.

The NMR data for the pentamethyl esters with $\mathrm{m} / \mathrm{z}=1021$ discussed above and presented in Tables 2 and 3 leave no doubt that both isomers D and $\mathrm{F}$ have the constitution $17^{2}$-methylthioF430 pentamethyl ester and are configurational isomers at $\mathrm{C} 17^{2}$.

Relative Configuration at $\mathbf{C 1 7}$ and $\mathbf{C 1 7}^{2}$. The absolute configuration at all stereogenic centers of F430 (1) from methanogens is known. Since the CD spectra of pentamethyl ester $\mathbf{2}$ from methanogens are almost superimposable to those of the $\mathrm{m} / \mathrm{z}=$ 1021 pentamethyl esters (isomers D and F, see Figure S3 in the Supporting Information), the absolute configuration in rings $\mathrm{A}, \mathrm{B}$, and $\mathrm{C}$ of the new variant must be the same as for coenzyme F430 from methanogens (1). Therefore, the deduction of the relative configuration at $\mathrm{C} 17$ and $\mathrm{C} 17^{2}$ from the NMR spectra of isomers $\mathrm{D}$ and $\mathrm{F}$ was sufficient to determine the absolute configuration of the additional stereogenic center at $\mathrm{C} 17^{2}$ in the new $\mathrm{m} / \mathrm{z}=951$ variant. A cross-peak between $\mathrm{H} 19$ and H17 in the ROESY spectra of both isomers D and F showed 

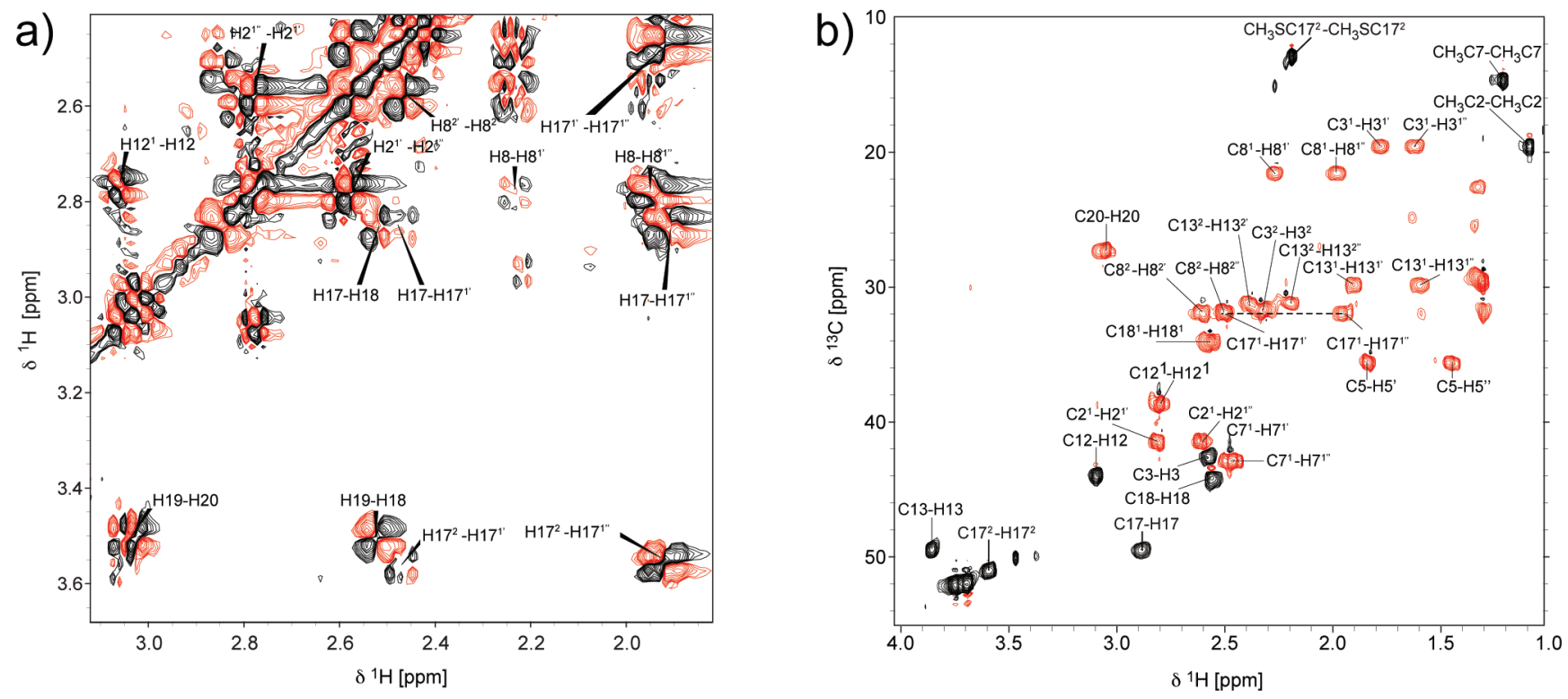

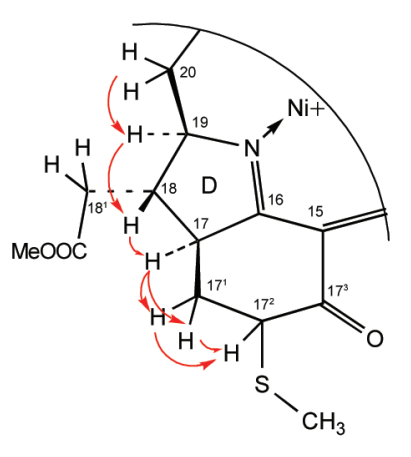

DQF-COSY

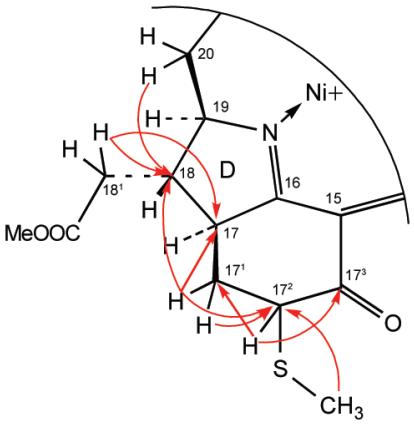

$\mathrm{HMBC}$

Figure 2. Expansions of (a) DQF-COSY, (b) multiplicity edited HSQC, and (c) HMBC spectra with the crucial correlations defining the constitution of pentamethyl ester 5 (isomer D).

that the configuration at $\mathrm{C} 17$ is $17 \mathrm{~S}$, unchanged relative to $\mathrm{F} 430$ from methanogens. In isomer $\mathrm{D}$, the signal of $\mathrm{H} 17^{1 \prime \prime}$ is discernible in the 1D spectrum as a quartet with three large coupling constants of ca. $12.5 \mathrm{~Hz}$ : one each with $\mathrm{H} 17$ and $\mathrm{H} 17^{2}$ in addition to the geminal coupling to $\mathrm{H} 17^{1}$ (Figure 3a). This requires that $\mathrm{H} 17, \mathrm{H} 17^{1 \prime \prime}$, and $\mathrm{H} 17^{2}$ are in a trans-trans quasitriaxial arrangement on the six-membered ring and, together with the observed NOEs, establishes the $17^{2} S$-configuration 5 for isomer D (Figure 3b).

For isomer $\mathrm{F}$, the two protons $\mathrm{H}_{17} 7^{1}$ are practically isochronous. The signal of $\mathrm{H}_{1} 7^{2}$ is a triplet with two small coupling constants of ca. $3 \mathrm{~Hz}$ each to the two $\mathrm{H}^{1} 7^{1}$ protons, indicating an equatorial orientation of $\mathrm{H}^{2} 7^{2}$. In contrast to isomer $\mathrm{D}$, no NOE is observed between $\mathrm{H} 17$ and $\mathrm{H}_{1} 7^{2}$ (Figure 4a). The coupling and NOE patterns observed in the six-membered ring of isomer $\mathrm{F}$ are consistent with the $17^{2} R$-configuration 6 as illustrated in Figure 4b.

NMR Spectroscopy of the Pentaacids with $m / z=951$. With the constitution and configuration of the two pentamethyl esters
5 and $\mathbf{6}$ in hand, the remaining task was to determine which one of the two stereoisomers corresponds to the native pentaacid contained in protein I. The HPLC chromatogram of raw isolate no. 3 from mats (see Figure S1b in the Supporting Information) showed two major peaks, one with $\mathrm{m} / \mathrm{z}=905$ and one with $\mathrm{m} / \mathrm{z}=951$ in a ratio of ca. 55:45, next to several minor components with either $\mathrm{m} / \mathrm{z}=905$ or $\mathrm{m} / \mathrm{z}=951$. After exhaustive desalting, the total isolate no. 3 was dissolved in trifluoroethanol- $d_{3}$ and analyzed as a mixture by NMR. As expected, the lines were somewhat broadened by residual paramagnetism and many cross-peaks of the two major components overlapped. Nevertheless, the DQF-COSY, TOCSY, and HSQC spectra indicated that the two major components were coenzyme F430 (1) and the $17^{2}$-methylthio derivative 3 corresponding to the $17^{2} S$-isomer of the pentamethyl ester (5), respectively.

Using two consecutive semipreparative HPLC separations on two different columns (see Experimental Section) it was eventually possible to isolate the $\mathrm{m} / \mathrm{z}=951$ pentaacids from 


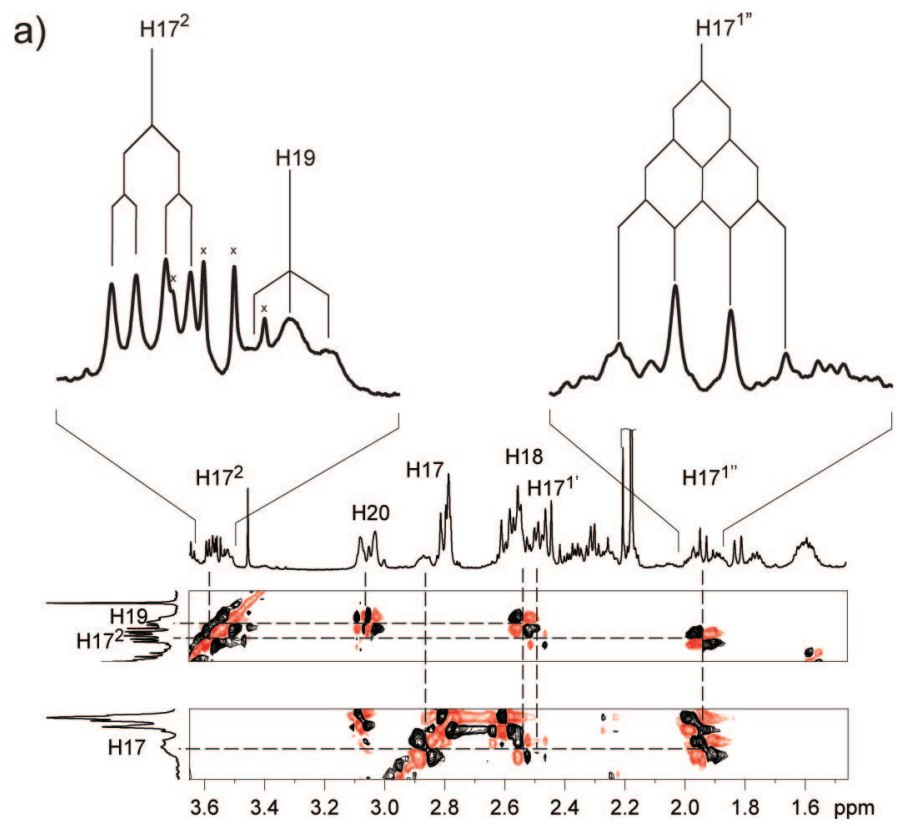

b)

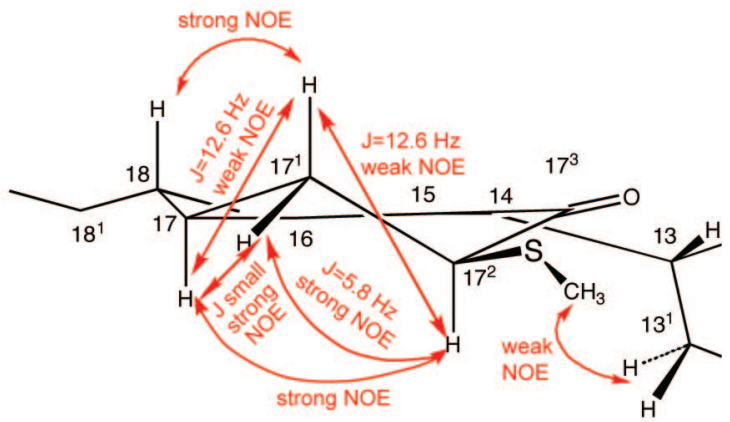

Figure 3. Crucial J-coupling and $2 \mathrm{D}$ correlations of the pentamethyl ester $\mathrm{m} / \mathrm{z}=1021$, isomer D (5). (a) Expansion of $1 \mathrm{D}{ }^{1} \mathrm{H}$ and COSY spectra. (b) View of the six-membered ring in perspective with NOE and $J$-coupling networks.

a)

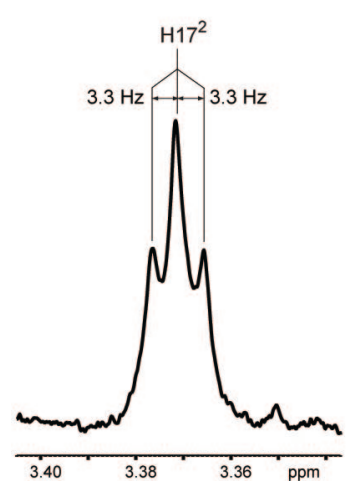

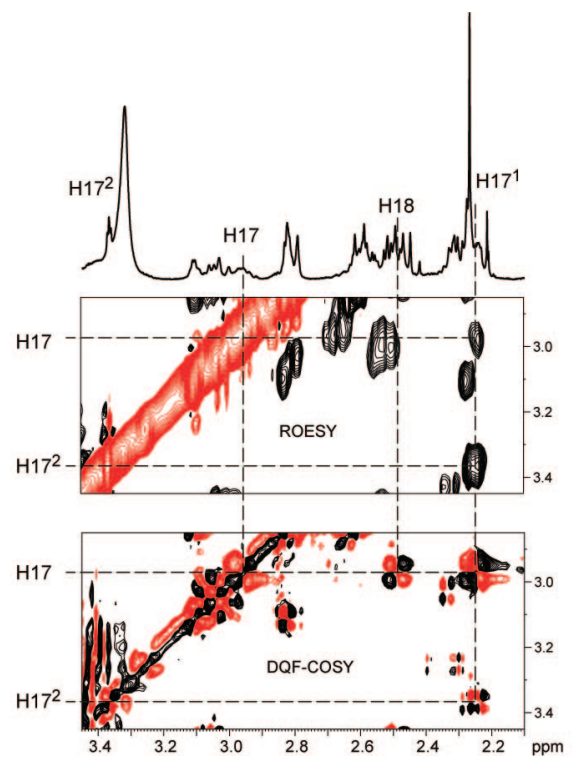

b)

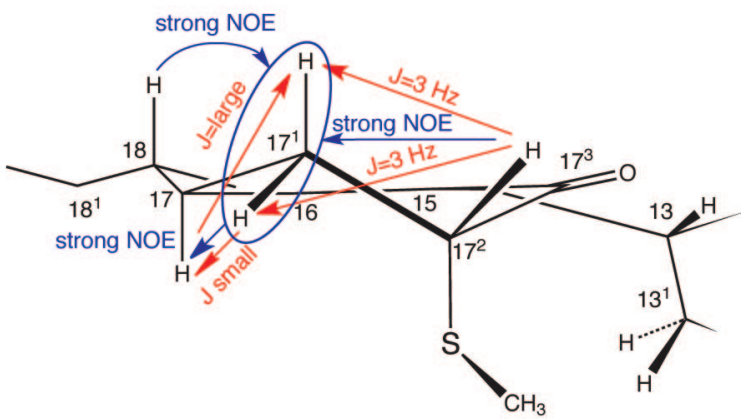

Figure 4. Crucial $J$-coupling and $2 \mathrm{D}$ correlations of the pentamethyl ester $m / z=1021$, isomer $\mathrm{F}(\mathbf{6})$. (a) Expansion of $1 \mathrm{D}{ }^{1} \mathrm{H}$, COSY and ROESY ( $t_{\mathrm{m}}=$ $300 \mathrm{~ms}$ ) spectra. (b) View of the six-membered ring in perspective with NOE and $J$-coupling networks.

isolate no. 3 in pure form and acquire a full set of NMR spectra (1D ${ }^{1} \mathrm{H},\left\{{ }^{1} \mathrm{H}\right\}-{ }^{13} \mathrm{C}, 2 \mathrm{D}$ DQF-COSY, edited HSQC, HMBC, TOCSY, ROESY with $t_{\mathrm{m}}=300 \mathrm{~ms}$ ) for the dominant isomer in TFE- $d_{3}$. Analysis of the correlations for this pentaacid independently confirmed the structure of $\left(17^{2} S\right)-17^{2}$-methylthiocoenzyme F430 (3) for the major component with $\mathrm{m} / \mathrm{z}=951$ in isolate no. 3. Because of the shorter $\mathrm{T}_{2}$-relaxation times induced by traces of paramagnetic species, some of the HMBC cross-peaks that were visible in the spectrum of the pentaester 5 could not be detected for the pentaacid 3. The assignments and chemical shifts, which differ only slightly from those of the pentaester, are listed in Tables 2 and 3.

Epimerization Studies and Correlation of the Pentaacid with the Pentaester Diastereoisomers. Because the configuration at $\mathrm{C} 17^{2}$ had been determined by NMR for the pentamethyl esters, the corresponding pentaacid diastereoisomers were correlated with the esters by mild hydrolysis of HPLC-pure pentamethyl esters $\mathbf{5}$ and $\mathbf{6}$ and HPLC analysis of the resulting pentaacids 3 and 4, respectively. Using the special HPLC conditions optimized for separation of the pentaacids, the initial relative amounts of the $17^{2} S-(3)$ and $17^{2} R-(4)$ isomeric pentaacids in isolates no. 2,3 , and 4 could be determined as follows: Isolate no. 2: $17^{2} S / 17^{2} R$ 46:54; isolate no. 3: $17^{2} S / 17^{2} R$ 90:10; isolate no. 4: $17^{2} S / 17^{2} R$ 74:26. Since the mat sample no. 2 had been treated more harshly during extraction than samples no. 3 and 4 (see Experimental Section) this already indicated that the $17^{2} R$-isomer might be an isolation artifact, caused by the long exposition to acidic conditions and by the heat of neutralization while extracting the isolates from mats. Analysis of the mixtures of pentamethyl esters obtained from isolates no. 2 and no. 4 indicated that the acidic esterification conditions led to additional conversion of $17^{2} S$-isomer into its $17^{2} R$-epimer during esteri- 


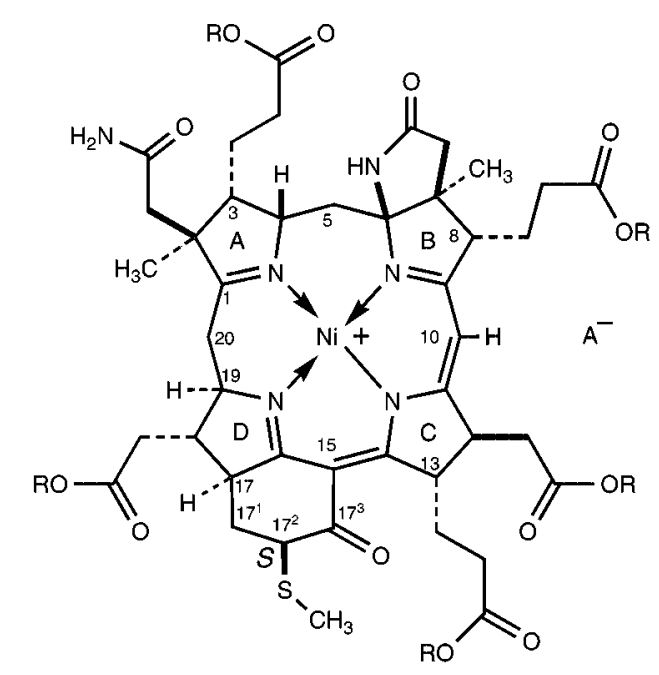

$3 \mathrm{R}=\mathrm{H} \quad\left(17^{2} S\right)-17^{2}$-methylthio-coenzyme F430

$5 \mathrm{R}=\mathrm{Me}\left(17^{2} \mathrm{~S}\right)-17^{2}$-methylthio-coenzyme F430 pentamethyl ester

\section{Native stereoisomer}

fication. ${ }^{18}$ Conversion of the $17^{2} S$-isomer into the $17^{2} R$-isomer under acidic conditions was verified by subjecting HPLC-pure $\left(<1 \%\right.$ 4) $17^{2} S$-pentaacid 3 to acidic conditions in the cold and analyzing the reaction mixture as a function of time: after 3 days, the $17^{2} S$ to $17^{2} R$ ratio was 41:59, after 7 days $22: 78$ and after 16 days 20:80 (see Figure S10 in the Supporting Information). Since this ratio did not change significantly within 13 more days, the last value must correspond to the thermodynamic equilibrium between the two isomers. Hence, the $17^{2} \mathrm{~S}$-isomer 3 is the native one whereas the $17^{2} R$-isomer 4 is the thermodynamically more stable one.

\section{Discussion}

The phylogenetic relationship between the dominant (7\% of total cell protein) Ni-protein I and MCR from methanogenic archaea is very similar to the one between the 16S rRNA of ANME-1 and of methanogenic archaea. ${ }^{15}$ This points to ANME-1 as the source of protein $\mathrm{I},{ }^{15}$ which contains the newly found variant 3 of coenzyme F430. Protein II, which contains the same nickel hydrocorphin as the methanogens, namely coenzyme F430 (1), is also relatively abundant (3\% of the total cell protein). Because the mat exhibited very low methanogenic activity, its association with contaminating methanogenic archaea is unlikely. Hence, protein II presumably stems from ANME- 2 cells. The microbial communities carrying out AOM always contained both ANME-1 and ANME-2 type archaea although their proportion in mats from different sources varied (with ANME-2 dominating in Hydrate Ridge sediments and ANME-1 dominating in the pink-colored Black Sea mats). ${ }^{19-21}$ This indicates that enzymes containing either cofactor $\mathbf{3}$ or $\mathbf{1}$ may catalyze the first step of anaerobic methane oxidation and that functionalization of the hydrocorphin macrocycle at $\mathrm{C} 17^{2}$

(18) Methylation of a part of isolate no. 2 in methanol $/ p$-TsOH at $50{ }^{\circ} \mathrm{C}$ for $3 \mathrm{~h}$ changed the $17^{2} S / 17^{2} \mathrm{R}$ ratio from $46: 54$ for the pentaacids to 23:77 for the pentaesters.

(19) Knittel, K.; Loesekann, T.; Boetius, A.; Kort, R.; Amann, R. Appl. Environ. Microbiol. 2005, 71, 467-479.

(20) Treude, T.; Orphan, V.; Knittel, K.; Gieseke, A.; House, C. H.; Boetius, A. Appl. Environ. Microbiol. 2007, 73, 2271-2283.

(21) Blumenberg, M.; Seifert, R.; Reitner, J.; Pape, T.; Michaelis, W. Proc. Natl. Acad. Sci. U.S.A. 2004, 101, 11111-11116.

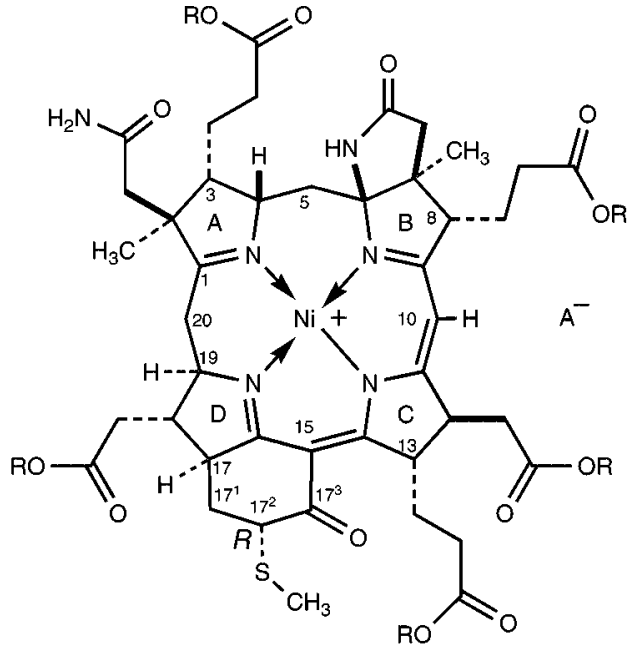

$4 \mathrm{R}=\mathrm{H} \quad\left(17^{2} R\right)-17^{2}$-methylthio-coenzyme F430

$6 R=\operatorname{Me}\left(17^{2} R\right)-17^{2}$-methylthio-coenzyme F430 pentamethyl ester

Thermodynamically more stable stereoisomer

with a methylthio group is not a mandatory requirement for this catalytic competence. The very small amounts of pure $\mathbf{3}$ (or 5) available so far did not allow investigation of the influence of the $17^{2}$-methylthio group on the physicochemical properties known to be relevant for the catalysis in methanogens, such as the $\mathrm{Ni}(\mathrm{II}) / \mathrm{Ni}$ (I) redox potential. ${ }^{22}$ On the basis of chemical reasoning, however, one would not expect this modification to have a substantial influence on the reactivity of the nickel center. ${ }^{23}$ Therefore, the possible functions of the $17^{2}$-methylthio substituent have to be considered in conjunction with the sequence differences, between protein I and MCR from methanogens. ${ }^{24}$ All conserved amino acids known to be involved in the active site of MCR were also present in the corresponding $\alpha-, \beta$-, and $\gamma$-chains of protein I. However, near the active site, the $\alpha$-chain showed a series of changes which, when modeled into the X-ray structure of $\mathrm{MCR}_{\mathrm{ox} 1 \text {-silent, are located along an }}$ $\alpha$-helix pointing exactly at the six-membered carbocycle of coenzyme F430 that carries the methylthio modification (Figure 5 ). In the $\alpha$-chain of protein I methylglutamine 400 , one of the five posttranslationally modified amino acids found in MCR from methanogens ${ }^{23}$ is mutated to a valine, and Ala 403, Val 404, Ala 409, and Phe 415 are mutated to cysteines. ${ }^{15,16}$ Within

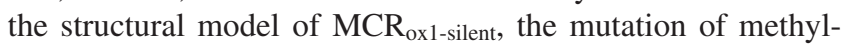
glutamine 400 to valine 400 in protein I prevents a steric clash between the methylthio group of $\mathbf{3}$ and the methylglutamine side chain.

As long as there is no X-ray structure of protein I, one can only speculate about the possible function of the $17^{2}$-methylthio substituent in $\mathbf{3}$ and the row of four cysteines replacing hydrophobic amino acids along the $\alpha$-helix. The sequence CCxxxxCxxxxxC does not correspond to a known motif for sulfur-metal clusters. If the secondary structure of protein I were indeed close to that of MCR from methanogens, a role in electron transport or coupled $\mathrm{H}^{+} / \mathrm{e}^{-}$transport appears to be the most likely. A channel for electron or $\mathrm{H}^{+} / \mathrm{e}^{-}$transport from the surface of the protein to the

(22) Jaun, B.; Pfaltz, A. J. Chem. Soc., Chem. Commun. 1986, 1327-1329.

(23) Jaun, B. Chimia 1994, 48, 50-55.

(24) Kahnt, J.; Buchenau, B.; Mahlert, F.; Krüger, M.; Shima, S.; Thauer, R. K. FEBS J. 2007, 274, 4913-4921. 


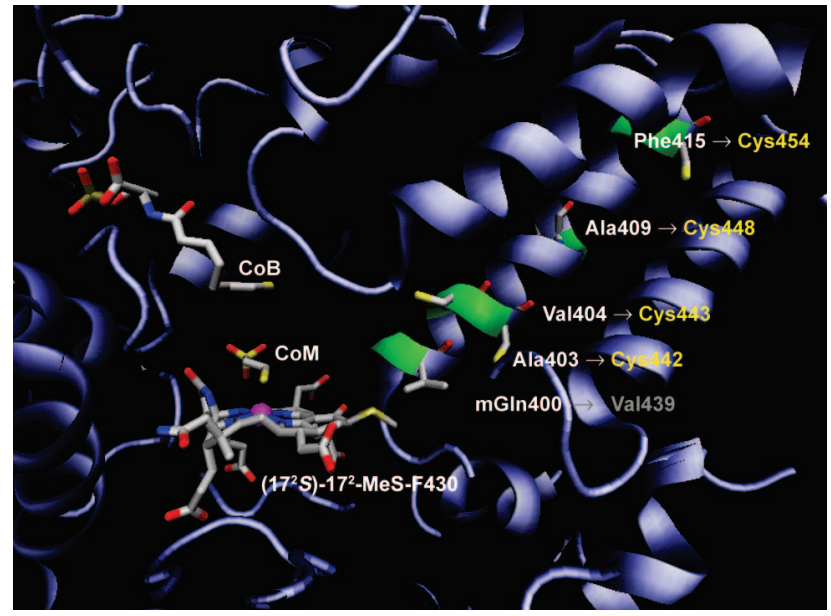

Figure 5. The mutations in chain A and the methylthio group at $\mathrm{C} 17^{2}$ of F430 variant modeled into the X-ray-structure of $\mathrm{MCR}_{\mathrm{ox} 1 \text {-silent, }}$ an inactive $\mathrm{Ni}(\mathrm{II})$ form of the enzyme from the methanogen Methanobacter thermoautotrophicum (PDB ID: 1mro). ${ }^{1,8}$

active site might be of importance in rescuing oxidized $\mathrm{Ni}$ (II) forms back to the active $\mathrm{Ni}(\mathrm{I})$ state.

\section{Experimental Section}

Mat Sampling. In the northwestern Black Sea microbial reefs (microbial mats) fuelled by anaerobic oxidation of methane occur along the shelf edge west of the Crimea peninsula at water depth between 35 and $800 \mathrm{~m} .{ }^{14}$ Samples from these reefs were retrieved during Black Sea cruises in 2001 (R/V Professor Logachev) (isolates no. 1 and 2) and 2004 (R/V POSEIDON, cruise POS 317-2) (isolates no. 3 and 4) using the manned submersible JAGO. With the manipulator of JAGO, pieces of the microbial mats were taken at $230 \mathrm{~m}$ water depth $\left(44^{\circ} 46^{\prime} \mathrm{N}, 31^{\circ} 60^{\prime} \mathrm{E}\right)$ under video control and stored in closable PVC barrels. Sampling barrels were opened on board within an anoxic chamber flooded with argon, and the samples were transferred into plastic bags or glass bottles $(100 \mathrm{~mL})$ sealed with butyl septa and stored frozen at $-37{ }^{\circ} \mathrm{C}$. Transport from the ship into the institute laboratory was realized within two days keeping the samples constantly frozen under dry ice.

1. F430 Extraction and Purification from Mats. Isolate no. 2 was extracted and purified differently (see Supporting Information) from isolates no. 1, 3, and 4 (see below), resulting in remarkably increased epimerization at $\mathrm{C} 13$ and $\mathrm{C} 12$ as well as $\mathrm{C}^{2} 7^{2}$ (see epimerization studies).

2. Isolates No. 1, 3, and 4. The mat samples consisted mainly of calcium carbonate, which was colonized by microbial layers. The method employed for the separation of the microbial cells from the carbonates and for the extraction and purification of F430 from the cells is described here for isolate no. 3. With small modifications this method was also employed for isolates no. 1 and 4 . The four samples differed mainly in their calcium carbonate content, indicating that they were from different parts (inside, outside, top, bottom) of the carbonate chimneys (microbial reefs) from which they were taken.

An aliquot of $300 \mathrm{~g}$ was thawed at $4{ }^{\circ} \mathrm{C}$ overnight, smashed to small pieces in a large mortar, and then suspended in $100 \mathrm{~mL}$ of distilled water, again at $4{ }^{\circ} \mathrm{C}$. After shaking for $10 \mathrm{~min}$ the insoluble carbonates were allowed to settle for $5 \mathrm{~min}$, and the supernatant containing the cell suspension was removed and centrifuged at $24000 \mathrm{~g}$ for $10 \mathrm{~min}$. The supernatant from this centrifugation step, which was almost colorless, was readded to the calcium carbonate sediment, and the procedure described above (shaking, sedimentation, removal of the supernatant, and centrifugation) was repeated four times until the supernatant from the sedimentation step was no longer turbid. Subsequently the pellets from the centrifugation steps were combined and suspended in the supernatant of the last centrifugation step. By this procedure ca. $250 \mathrm{~mL}$ suspension of microbial mat cells (approximately $8 \mathrm{~g}$ protein) was obtained, leaving behind $150 \mathrm{~g}$ calcium carbonate and other rapidly sedimenting material.

To extract the $\mathrm{F} 430$ from the cells, the $250 \mathrm{~mL}$ suspension, adjusted to $\mathrm{pH} 7$ with $\mathrm{KOH}$, was ultrasonicated for 20 min with a titanium plate at maximal power, keeping the temperature near $4{ }^{\circ} \mathrm{C}$ by cooling in an ice bath, and then centrifuged for $30 \mathrm{~min}$ at $24000 \mathrm{~g}$. The pellet was resuspended in $100 \mathrm{~mL}$ of $\mathrm{H}_{2} \mathrm{O}$ and the $\mathrm{pH}$ adjusted to 3.0 with formic acid. This suspension was sonicated and centrifuged again as described. The pellet from the second centrifugation step was resuspended in $100 \mathrm{~mL}$ of $1 \%$ formic acid and the suspension shaken for $20 \mathrm{~min}$ at $4{ }^{\circ} \mathrm{C}$ and centrifuged. Subsequently the three supernatants were combined (ca. $500 \mathrm{~mL}$ ), adjusted to $\mathrm{pH} 7$ with $\mathrm{KOH}$, diluted 1:1 with water, and centrifuged to remove precipitated material. A $500 \mathrm{~mL}$ amount of the supernatant was applied to a QAE Sephadex A25 column $(3 \mathrm{~cm} \times 20 \mathrm{~cm})$ equilibrated with $50 \mathrm{mM}$ Tris/ $\mathrm{HCl} \mathrm{pH}$ 7.5. From this column, F430 was eluted with $20 \mathrm{mM}$ formic acid. The fractions containing F430 (ca. $300 \mathrm{~mL}$ ) were combined and applied to a XAD (PAD I) column $(1 \mathrm{~cm} \times 10 \mathrm{~cm})$ equilibrated with $10 \mathrm{mM}$ formic acid. After washing with $10 \mathrm{mM}$ formic acid, F430 was eluted with $100 \%$ methanol. The F430 solution was concentrated in a vacuum centrifuge and residual methanol removed by lyophilization. The F430 yield was determined spectrophotometrically $\left(\epsilon_{430}=22.5 \mathrm{mM}^{-1}\right.$ $\mathrm{cm}^{-1}$ ).

High Resolution MALDI-ICR MS. MALDI samples containing pentaacids and/or pentaesters were prepared in $\mathrm{CH}_{3} \mathrm{OH} / \mathrm{H}_{2} \mathrm{O}$ 1:1 saturated with $\alpha$-cyano-4-hydroxycinnamic acid (4-CCA) matrix. All measurements took place in positive ion mode on an IonSpec 4.7 T Ultima FT-ICR mass spectrometer. For two-point calibration, coenzyme F430 pentamethyl ester $(\mathbf{1}, \mathrm{m} / \mathrm{z}=975.36446)$ was added to isolate no. 2 from mats, and it was assumed that the peak at $\mathrm{m} / \mathrm{z}$. $=905$ corresponds to F430 (2) with $\mathrm{m} / \mathrm{z}=905.28621$ (as independently verified by coinjection in HPLC). The exact mass difference between the $\mathrm{m} / \mathrm{z}=951$ and $\mathrm{m} / \mathrm{z}=905$ peaks was $45.99014 \pm 0.003$ Da.

MALDI-TOF MS. To identify HPLC-pure pentaacids, pentaesters, and the corresponding mixtures, a solution of methanol in $\mathrm{H}_{2} \mathrm{O}(50 \%$ v/v) saturated with $\alpha$-cyano-4-hydroxycinnamic acid (4CCA) was applied as matrix. For the pentaesters we alternatively used a diluted solution of trans-2-[3-(4-tert-butylphenyl)-2-methyl2-propenylidene)malononitrile] (DCTB) in dichloromethane as matrix. All measurements were performed in positive ion mode on a Bruker Ultraflex II mass spectrometer.

Ni/S Ratio Determination Using LA-ICP-SF MS. Nickel to sulfur ratios were determined using laser ablation inductively coupled plasma sector field mass spectrometry (LA-ICP-SF MS). ${ }^{25}$ An excimer laser ablation system (GeoLasM, Coherent Lambda Physik, Göttingen, Germany) was coupled to a sector-field-ICP MS (Thermo Fisher, Bremen, Germany), which was operated in medium resolution $(m / \Delta m=4000)$ to resolve ${ }^{32} \mathrm{~S}^{+}$from ${ }^{16} \mathrm{O}^{16} \mathrm{O}^{+}{ }^{26}$ For the analysis, HPLC separated samples were dried as spots on a SUPRASIL quartz plate (see Figure S11 in Supporting Information) and directly ablated using single line scanning mode. The laser fluence was adjusted to $5 \mathrm{~J} / \mathrm{cm}^{2}$ at $80 \mu \mathrm{m}$ crater diameter, and a repetition rate of $5 \mathrm{~Hz}$ was applied for sampling. Transient signals were acquired over a period of $40 \mathrm{~s}$ in single line scanning mode. Each sample was analyzed ( $n=4$ or 8 ), and a blank sample (F430 pentamethyl ester (2)) was included to determine sample-matched background intensities on $\mathrm{S}$ and $\mathrm{Ni}$ isotopes. Mass ratios were quantified using NIST SRM 610 and cross-validated for S using a sulfur-containing scapolith mineral $\mathrm{R} 1$. The $\mathrm{Ni} / \mathrm{S}$ mass ratio of isolate no. 3 was determined in two different analysis sequences $(n=14)$ giving $4.40 \pm 0.27$ (RSD: $6.2 \%, n=4)$ and $4.30 \pm 0.29$ (RSD: $6.7 \%, n=10$ ). The Ni/S mass ratio in the pentamethyl ester isomer $\mathrm{F}(6)$ was $1.85 \pm 0.18$ (RSD: $9.4 \%, n=4)$.

(25) Günther, D.; Hattendorf, B. Trends Anal. Chem. 2005, 24, 255-265. (26) Latkoczy, C.; Günther, D. J. Anal. Atom. Spectrom. 2002, 17, 1264 1270 . 
Desalting. The pentacarboxylic acid F430 and its corresponding derivatives were separated from salts on SPE cartridges containing between $10 \mathrm{mg}$ (volume $1 \mathrm{~cm}^{3}$ ) and $6 \mathrm{~g}$ (volume $35 \mathrm{~cm}^{3}$ ) of a hydrophilic-lipophilic balanced (HLB) reverse-phase sorbent with sufficient resistance to strong acids (for the detailed procedure, see Supporting Information).

Esterification of Isolate No. 4. About $4.4 \mu \mathrm{mol}$ of crude isolate no. 4 was dissolved gradually in $2 \mathrm{~mL}$ of methanol containing 30 mg of $p$-toluenesulfonic acid monohydrate ( $p$-TsOH). Methanol was freshly distilled from metallic magnesium, and $p-\mathrm{TsOH}$ was dried by dissolving the monohydrate in toluene and evaporating the solvent (three times). The dark-brown solution was divided into two $1 \mathrm{~mL}$ portions, and each was placed in a cylindrical ampule with a Young Teflon valve on top and degassed by three freeze-pump-thaw cycles. Both ampules were kept under vacuum and heated in an oil bath at $40{ }^{\circ} \mathrm{C}$ for $3.5 \mathrm{~h}$. Afterward the two batches were cooled to $0{ }^{\circ} \mathrm{C}$ and each diluted with $1 \mathrm{~mL}$ of $0.1 \mathrm{M}$ $\mathrm{NaClO}_{4}$ in $\mathrm{HClO}_{4} / \mathrm{H}_{2} \mathrm{O}(\mathrm{pH}$ 2.3). The aqueous phases were extracted three times with $\mathrm{CH}_{2} \mathrm{Cl}_{2}$ in centrifuge tubes, and after centrifugation for $30 \mathrm{~s}$, the organic phases were removed with a gastight syringe, filtered through cotton wool, and evaporated to dryness. Within the detection limit, the remaining aqueous phase did not show any absorption at $430 \mathrm{~nm}(d=1 \mathrm{~cm})$. Therefore the yield of esterification was considered to be $>99 \%$.

Hydrolysis of Pentamethyl Esters. Conversion of Pentaacid 3 to the Thermodynamic Equilibrium Mixture of 3 and 5. In two parallel experiments, 50-100 nmol of the HPLC-pure pentamethyl esters $\mathbf{5}$ and $\mathbf{6}$, respectively, was dissolved in $20 \% \mathrm{H}_{2} \mathrm{SO}_{4}$ $(c \leq 0.1 \mathrm{mM})$, placed in a cylindrical ampule $(150 \mathrm{~mm} \times 8 \mathrm{~mm}$ i.d.) with a Young Teflon valve on top, and degassed by three freeze-pump-thaw cycles. After exhaustive hydrolysis for 3 days at $4{ }^{\circ} \mathrm{C}$, the free acids were separated from sulfuric acid by adsorption at SPE-HLB sorbents, eluted with methanol, and evaporated to dryness.

For equilibration experiments, a solution of $50 \mathrm{nmol}$ of pentacarboxylic acid 3 in $2 \mathrm{~mL}$ of $20 \% \mathrm{H}_{2} \mathrm{SO}_{4}$ was placed in a cylindrical flask $(160 \mathrm{~mm} \times 20 \mathrm{~mm}$ i.d.) with a Young Teflon valve on top and degassed by three freeze-pump-thaw cycles. After 3, 7, 16, and 29 days, the ampule was opened under a nitrogen atmosphere, and aliquots of $500 \mu \mathrm{L}$ of the acidic solution were taken for the determination of the molar ratio of the two epimeric methylthiopentaacids by RP-HPLC.

HPLC Separation of Pentamethyl Esters and Pentacarboxylic Acid. For the detailed HPLC procedures, see Supporting Information. Esterified isolate no. 4 ( $4.4 \mu \mathrm{mol}$, pentamethyl esters) was separated on a Chromolith SemiPrep RP column with a gradient of aq $0.1 \mathrm{M} \mathrm{NaClO}_{4} /$ acetonitrile. Isolate no. $3(2.5 \mu \mathrm{mol}$, pentacarboxylic acids) was separated by to consecutive HPLC stages, first on Chromolith SemiPrep RP-18e with a gradient of $0.1 \mathrm{M} \mathrm{NaClO}_{4}$ in $\mathrm{HClO}_{4} / \mathrm{H}_{2} \mathrm{O}(\mathrm{pH} 2.3) /$ acetonitrile and then on HYPERCARB with a gradient of $\mathrm{HClO}_{4} / \mathrm{H}_{2} \mathrm{O}(\mathrm{pH}$ 1.0) /acetonitrile. To determine the equilibrium between $\mathbf{3}$ and $\mathbf{4}$, the same chromatographic procedure via a HYPERCARB column was used as described above for the second separation stage for the pentacarboxylic acids.

UV/vis and CD Spectroscopy. UV/vis spectra were measured on a two-channel Lambda 20 Spectrometer (Perkin-Elmer) in quartz cells $(d=0.1$ or $1 \mathrm{~cm})$ with pure solvent in the reference cell. CD spectra were measured on a JASCO J-170 spectropolarimeter in quartz $(d=0.1 \mathrm{~cm})$ cells and smoothed with support of JASCO Spectra Manager (version 1.53.00). Concentrations of pentaacids as well as pentaesters of F430 and its derivatives were adjusted to an absorbance of $0.7-1.0$ at $435 \mathrm{~nm}$ (free acids in methanol) and $442 \mathrm{~nm}$ (pentamethyl esters in dichloromethane), respectively. Parameters: bandwidth $1.0 \mathrm{~nm}$; response $0.5 \mathrm{~s}$; data pitch $0.1 \mathrm{~nm}$; scanning speed $100 \mathrm{~nm} / \mathrm{min}$; accumulation 4 ; temperature $20^{\circ} \mathrm{C}$.

NMR Spectroscopy. ${ }^{1} \mathrm{H}$ and ${ }^{13} \mathrm{C}$ NMR spectra were recorded on Bruker Avance-II spectrometers at $600 / 150 \mathrm{MHz}$ and $700 / 175$
$\mathrm{MHz}$ with $5 \mathrm{~mm}$ cryoprobes of type DCH and TCI. Chemical shifts are referenced to the signals of $\mathrm{CF}_{3} \mathrm{CD}_{2} \mathrm{OD}\left({ }^{13} \mathrm{C}: \delta=58.7 \mathrm{ppm}\right)$ and $\mathrm{CF}_{3} \mathrm{CHDOD}\left({ }^{1} \mathrm{H}: \delta=3.92 \mathrm{ppm}\right)$. NMR parameters for individual experiments: see table S7 in the Supporting Information. $2 \mathrm{D}$ spectra were analyzed and assigned with the aid of SPARKY. ${ }^{27}$

1. Sample Preparation for Pentaesters in $\mathrm{CD}_{2} \mathrm{Cl}_{2} / \mathrm{TFE}-d_{3}$ 80:20 (v/v). After purification by semipreparative RP-HPLC, the configurational isomers $\mathrm{D}$ and $\mathrm{F}$ were desalted with SPE-HLB cartridges as described above for pentaesters. To remove all traces of nondeuterated solvents, both isomers were dissolved three times in $\mathrm{CD}_{2} \mathrm{Cl}_{2}$, and the solvent was afterward evaporated. About 600 nmol of each compound was thoroughly dried and then dissolved in $120 \mu \mathrm{L}$ of $\mathrm{CD}_{2} \mathrm{Cl}_{2} / \mathrm{TFE}-d_{3}$ 80:20 (v/v). The dark-brown solutions were transferred into a $3 \mathrm{~mm}$ Shigemi NMR tube CMS (specified for $\mathrm{CDCl}_{3}$ ) through a glass pipet containing a cellulose filter. The column of liquid in the Shigemi tube was $20 \mathrm{~mm}$. All described operations were carried out in a glovebag under $\mathrm{N}_{2}$. NMR measurements of isomer D were done in two periods of instrument time separated by several weeks. Before the second measurement, the compound was repurified by preparative thin layer chromatography (TLC) (see ref 6).

2. Sample Preparation for Pentaacids and Raw Isolates in TFE- $\boldsymbol{d}_{3}$. A $560 \mathrm{nmol}$ amount of a RP-HPLC purified component of isolate no. 3 as well as the crude extract itself (about $2.5 \mu \mathrm{mol}$ ) was desalted with SPE-HLB cartridges as described above for pentaacids. To ensure that all the pentacarboxylic acids keep their solubility in 2,2,2-trifluoroethanol (TFE), the hydrocorphinoid nickel complexes were eluted with methanol/TFE 1:1 (v/v). To remove all traces of nondeuterated solvents, samples were dissolved three times in TFE- $d_{3}$, and the solvent was afterward evaporated. Filtration and transfer of the samples into the $3 \mathrm{~mm}$ Shigemi NMR tube MMS (specified for $\mathrm{CD}_{3} \mathrm{OD}$ ) were carried out in the same way as described above for the pentaesters.

Acknowledgment. The present work was supported by the Swiss National Science Foundation (Grant Nr. 200020-111650). B.J. and S.M. thank H. Altorfer for helpful discussions, W. Amrein, R. Häfliger, O. Scheidegger, and L. Bertschi for acquiring the high resolution mass spectra, and D. Moskau and R. Kümmerle, Bruker Biospin AG, Fällanden, Switzerland, for instrument time on 700 and $600 \mathrm{MHz}$ NMR spectrometers with cryoprobes. Furthermore, we are indebted to T. Mäder for excellent technical support. We thank W. Michaelis and R. Seifert for opening access to the Black Sea samples. The crews of R/V Professor Logatchev, R/V Poseidon and JAGO, and Katja Nauhaus are acknowledged for their support during field work. Cruises and work on samples were supported by the projects GHOSTDABS, MUMM (BMBF/DFG program GEOTECHNOLOGIEN), and BEBOP (University of Hamburg).

Supporting Information Available: Analytical workflow for isolates no. 1-4; RP-HPLC-chromatogram of raw isolates no. 2 and 3; high-resolution mass analysis; UV/vis and CD spectra; tables with the 2D correlations of $\mathbf{5}, \mathbf{6}$, and $\mathbf{3}$; selected NMR spectra $(1 \mathrm{D}, 2 \mathrm{D})$ of pentamethyl esters $\mathbf{5}$ and $\mathbf{6}$ in TFE- $d_{3} /$ $\mathrm{CD}_{2} \mathrm{Cl}_{2}$ as well as of the pentaacid 3 in TFE- $d_{3}$; NMR parameters; partial epimerization of pentacarboxylic acid $\mathbf{3}$ to equilibrium in $\mathrm{H}_{2} \mathrm{SO}_{4}$; spot plate for ICP-MS analysis. This material is available free of charge via the Internet at http:// pubs.acs.org.

JA802929Z

(27) Goddard, T. D.; Kneller, D. G. Program SPARKY 3, University of California, San Francisco. 